\title{
Interpreting the Significance of Underwater Archaeological Photogrammetry
}

\section{Persefoni Lesgidi}

MSc Maritime Archaeology, University of Southampton.p.les@hotmail.com

\begin{abstract}
Photogrammetry has long been recognised as one of the most effective methods for documenting, collecting, and processing cultural heritage. This paper aims to study underwater photogrammetry by examining articles and interactive platforms related to this subject. Specifically, it focuses on the case study of the Mazotos shipwreck in order to identify the ways archaeologists use photogrammetry underwater and its importance in maritime archaeology. In this paper, the multiple challenges and limitations of photogrammetry are also presented, along with the actions that can be done to mitigate these problems.
\end{abstract}

\section{Key words}

Archaeology, underwater, photogrammetry, photography, Mazotos, shipwreck

\section{Introduction}

The paper focuses on the interpretation of photogrammetry in maritime archaeology. I originally researched this topic for my MSc thesis in Maritime Archaeology at the University of Southampton. The data in the tables which are presented in the following pages were collected between 26 August and 1 September, 2018.

In 1960, Robert Colwell stated that 'Photographic interpretation currently is proving to be unexcelled as an information-gathering process in an extremely wide variety of fields, ranging from geography to archaeology and its value is widely recognised in both military and civil circles' (Moffitt, 1970: 1). This study is rooted in 
his words about interpretation, but not in connection with photography; instead, it is concerned with photogrammetry, a field that has its origins in photography. Photogrammetry provides physical reconstructions such as 3D models, that people can interpret easily in their own time.

Documentation in archaeology has always been a subject of discussion among experts, since archaeology constitutes the basic record of activities of the human past. Before and during the destructive practice of excavation, or simply in the course of a non-invasive survey, archaeologists meticulously record the site in order to gain all the relevant information and keep data for future reference, as sites can change over time (Bowens, 2009: 53). Consequently, the principal aim of this work is the identification of the ways archaeologists use photogrammetry underwater, along with the motives behind that use, so as to distinguish its importance in the field.

Photogrammetry is the art and science of deriving accurate 3D metric and descriptive object information by means of multiple analogue and digital images (Al-Ruzouq, 2012: 97, 104). It is based on the principles of geometry and relies on overlapping photographs taken from different perspectives and distances between the site or object and the camera, in order to establish the dimensions of the site or object. Traditionally, these dimensions were represented on maps and plans as elevations, facades, and/or contours (Al-Ruzouq, 2012: 97 , 104). The methodology of photogrammetry follows from the moment the picture is taken, until dissemination to academia and public engagement via virtual tours (Fig. 1). A product of photogrammetry is the photomosaic that is produced by a series of overlapping images joined together, traditionally printed, to provide measurements (Bowens, 2009: 78). A great example is the excavation of the Batavia wreck (1973), where pictures were taken underwater with a 70\% overlap and then printed and joined together. As a result, a site photomosaic was created to give a better understanding of the site to archaeologists (Fig. 2) (Baker and Green, 1976: 146).

Since 1858, photogrammetric techniques have appeared in terrestrial archaeology (Albertz, 2001: 19); however, aerial photogrammetry was already in use earlier in the century (1800s) to provide topographic information for map making and photo-mosaics constituted by the assembly of a series of photographs into one continuous picture (Moffitt, 1970: 1; Dostal and Yamafune, 2018: 431). The first underwater project that used a preliminary photogrammetric method was George Bass's excavation of the shipwreck at Cape Gelidonya in 1960 (Fig. 3). A photographic montage was created when his team started to map the wreck (Bass and Van Doorninck, 1967: 25).

In 1963, stereophotogrammetry1 was used for the first time in an underwater expedition of the Byzantine wreck found at Yassi Ada. Two aerial survey cameras were mounted on the submarine Asherah that took the first stereoscopic photographs of the wreck at a depth of $35 \mathrm{~m}$ (Bass and Van Doorninck, 1969: 13-14). While photogrammetry has the same aim as conventional methods using tape-measures and trilateration, the methodology and technology used are different and the resulting data are more accurate. A photogrammetric

\footnotetext{
${ }^{1}$ The ability of the human brain to turn two pictures of the same object taken from two points of view, into a solid, three-dimensional object, is known as stereoscopy. Stereo photogrammetry is concerned with obtaining precise three dimensional $(X, Y, Z$ ) coordinates of common discrete points appearing on a stereoscopic pair of images (Adams and Spirakis, 1997).
} 
model is considered to provide better results than photographs as archaeologists can work faster and more effectively by seeing the results on screen in the form of a 3D model from which they can take digital measurements. This is due to the models' texture, which can have greater detail, surface texture and colour information (Agisoft, 2018). It can therefore be said that these characteristics can improve the way archaeologists' understand a site and change the way they view archaeology. Another application of photogrammetry is in the raising of public awareness by public engagement, one of the primary reasons why researchers conduct archaeology.

\section{Aims and Objectives}

The research topics that this study seeks to understand are:

- the significance of photogrammetric usage in underwater projects

- the way people practice photogrammetry

- the motives behind the use of photogrammetry

- how people interpret archaeological photogrammetric models

The impact that photogrammetry has on maritime archaeological projects, as well as how it affects the way people think and understand archaeology, are some issues that will be examined in the following text. In order to examine and answer the aforementioned issues and questions, a specific methodological approach has been employed and is discussed in the next section.

\section{Research Methodology \& Analysis}

Firstly, systematic research was conducted through two main sources: journal articles and the platform Sketchfab in order to collect information about the variety of archaeological projects that have used photogrammetry as their primary or supporting method of recording. Secondly, the Mazotos shipwreck was used as a case study, so as to identify whether archaeologists used all the functions that photogrammetry offers: for example, investigating, recording and documenting the site, measurement-taking, production of 3D models, creation of a site-plan or site-drawing, illustrating the excavation process (via 3D models or photo-mosaics), as well as dissemination and public engagement.

The Mazotos wreck was chosen as a case study, as the archaeologists have used photogrammetry as the primary way of recording. Furthermore, the two articles about this wreck (Demesticha, 2009; Demesticha, 2010) have a high level of engagement, with 178 and 243 views respectively (Demesticha, 2009; Demesticha, 2010). Demesticha's 2009 article that analyses the the ship's use in trade has a PaperRank2 of 2.9, the result of many recommendations.

The focus of the research is based on shipwrecks and not artefacts or parts of shipwrecks. This happens because shipwrecks are considered as 'time capsules' due to the great amount of information that they can provide us

\footnotetext{
2 The PaperRank of a paper is a function of the number of recommendations the paper has received, weighted by the AuthorRanks of the recommenders. A PaperRank of 10 is better than a PaperRank of 1 . However, there is no upper limit on PaperRank (Academia, 2019).
} 
(Muckelroy, 1978: 56), along with the fact that they are so fragile and important, that their documentation is absolutely crucial. After conducting the research, two databases were generated encompassing all the information gathered from the two main sources: Table 1 shows information from journal articles and Table 2 shows information from Sketchfab. For the readers' convenience, I decided to share the table online as follows:

Table 1: https://1drv.ms/x/s!Av5VFeWTIJYWjDdLrbcdDVNNbspv and Table 2: https://1drv.ms/x/s!Av5VFeWTIJYWjDsrAs9uzE6ZomUa.

Table 1 analyses the wreck sites whereas Table 2 focuses on the corporation or organisation that conducted research on a site. The data in both tables are classified by the name of each site, the date of the excavation, the date of the photogrammetric process, location, size and the dating of the site. The topography of the seabed is also specified each time as well as the visibility - if it was low or high. Logistics such as the depth, the bottom time, as well as the size of the project and the funding resources are included, as aids to understanding the projects' impact. The software or appropriate tool used for the development of the model is also included in the list, along with the number of photographs that were taken and the nature of the photogrammetric method; if it was used as a primary method or not. Finally, the duration of the work and the nature of the group that performed the survey or excavation was taken into consideration, as in some cases the use of photogrammetry was so effective that results were obtained in a short period. Since the work is not always carried out by professional archaeologists, it was important to record the backgrounds of the people involved in the projects, such as volunteers, students, or members of the public. Additional interactive information is listed in Table 2, such as views and comments, to indicate the importance of the platform's analysis.

The majority of information has been found in journals, using the keywords 'photogrammetry' and 'underwater photogrammetry archaeology'. The main journal that was used for research was the International Journal of Nautical Archaeology (IJNA), which is the most in-depth journal about maritime archaeology, in which there were found 60 article results. Thirty-four articles were encountered in the Journal of Archaeological Science, and 39 in The Photogrammetric Record. The information collected from the articles can be found in Table 1: https://1drv.ms/x/s!Av5VFeWTIJYWjDdLrbcdDVNNbspv.

The platform Sketchfab was chosen for research due to the fact that nowadays work is becoming more and more digitised and researchers seem to appreciate this platform. Additionally, it is very commonly used by archaeologists because it is free, easy to use, and provides interactive information about people such as likes, comments, and views, facts that add another aspect to our understanding. Sketchfab is the home of a million models, so filters were used to eliminate irrelevant results, and focus only on what was important in this study. Therefore, the category 'cultural heritage \& history' was examined by using the tag 'shipwreck'. Then, the field 'collections' was selected instead of models, otherwise the results would have been unlimited. Since the results gained were not adequate, the tag 'shipwrecks' was used. This produced few results, so the tag 'wrecks' was used, which consequently gathered nine collection results. However, the author was aware of the existence of more shipwreck models that were not found in the previous research; therefore, it was decided to use one of the tags in common with most of the shipwrecks in the table. Consequently, the tag 'archaeology' was used and the results were surprising. The collections had more than three hundred models. According to this, it was decided 
to examine the 'users' option, an option that was inaccessible earlier in the process. There were 81 users found, some of whom had no uploaded models and some of whom had artefacts or non-relevant items for the subject models. The organisations that were applicable with the study were finally recorded in Table 2: https://1drv.ms/x/s!Av5VFeWTIJYWjDsrAs9uzE6ZomUa totalling 57 organisations.

\section{Mazotos Case Study and Analysis}

Mazotos is a shipwreck site that is situated around $23 \mathrm{~km}$ south-west of Larnaca in Cyprus (Fig. 4). It lies at 45 $m$ depth on a flat sandy sea-bottom and dates to the third quarter of the 4th century BC. The dimensions of the site are $17.5 \times 8 \mathrm{~m}$ and it is covered by three layers of amphorae with an additional layer fully buried in the bottom of the seabed. It is considered a significant site due to its preserved condition along with its almost undisturbed concentration of amphorae. Mazotos constitutes the first Cypriot-led underwater archaeological project. The survey started in November, 2007, and its excavation started in 2010, continuing until today (Skarlatos et al., 2012: 4).

The primary aim of the Mazotos project was the mapping of the site in order to document its position, along with the position of each amphora, and the production of a 3D photogrammetric model. During the project seasons, the daily monitoring of the trenches along with the mapping of the artefacts was an additional aim to lead to the creation of a 3D reconstruction of the full excavation of the wreck (Fig. 5). As a result, an overview of the entire site could be produced, prior to the disturbance of the site by excavation. Digital photogrammetry was chosen as the primary technique for surveying the site during the pre-disturbance survey (Demesticha $e t$ al., 2014: 139-141). During 2007, two hundred and thirty photographs were taken in a single dive with 50\% overlapping, in order to produce a photomosaic that could provide a clear overview of the site. The tagging of all the amphorae was considered time-consuming and the half-exposed amphorae were not very visible in the photographs, creating issues and delays to the photogrammetric process. Thus, it was decided to produce the full mapping of the area during future seasons (Demesticha et al., 2014: 143-144).

During the excavation period in 2012, a local reference system was created. The team combined photographs from the pre-disturbance season so as to create a photomosaic and a 3D model of the wreck. The positions of plastic stoppers that had been placed in amphorae mouths, and additional control points that had been established in previous years, were used to georeference the 3D model with metric accuracy3 (Demesticha et al., 2014: 143). From the photomosaic more than 500 amphorae were counted, which led to the suggestion that they originated from Chios island (Fig. 7) (Demesticha, 2010: 40-41).

In this case, the 3D model was used as a tool by the archaeologists for the interpretation and understanding of the whole site, along with its cargo. In addition, the photogrammetric method and the open-source software was proven accurate and efficient in producing a 3D model of the site in a short period of time (Demesticha, 2010: 56). Photo-mosaics were considered significant for communication with the divers and for the planning of the excavation, as they could show the specific parts of the wreck that divers should visit and work on. Additionally,

\footnotetext{
${ }^{3}$ The method for generating a digital model from single 3D acquisitions involves the propagation of errors. These errors limit the overall metric accuracy attainable with such a procedure (J.-A. Beraldin 2002).
} 
they were simple and were rapidly created, whilst at the same time were considered a valuable resource for the interpretation of the site, in comparison with orthophotomosaics that required at least 10 days of processing time, post-processing, and editing. The layout of photography was simple and the method was fast even though it used a large number of photographs. The data quality was more accurate, less noisy, and much denser. Furthermore, the potential of computer vision techniques for investigation of the site and its internal stratigraphy exceeded archaeologists' expectations (Demesticha et al., 2014: 148).

The overall process seemed to have facilitated archaeological work underwater, since it sped up the practice, providing accurate results and proving to be a low-cost solution. The traditional approach of tape measurements at this depth was proven inaccurate and the photomosaic that was produced during the first survey season was not georeferenced, but archaeologists were able to manually extract a 2-dimensional site-plan (Fig. 8). The site was interpreted by divers using the photomosaic that was produced.

Consequently, the chosen case study of the Mazotos wreck meets the requirements that were set in the beginning of this study, as it used photogrammetry to map and record the site, along with illustrating the excavation process with photomosaics. Measurements of the site and the amphorae were taken, site-plans were created, and the observation-interpretation of the site in the pre-disturbance period was successful. Furthermore, the numerous publications archaeologists produced ticks the requirements of dissemination since, as mentioned earlier, many people have viewed and engaged with the Mazotos wreck articles.

The lack of public engagement through the 3D model might be its only weakness, since there was no additional link, neither was a 3D model uploaded to an interactive platform for people to see. Thus, the Mazotos team only engaged the academic community and not the public. A possible explanation for that might be the impact of funding, which plays a crucial role in underwater excavations. Another obstacle might be the fear of publicising the site's location to the public, which could lead to disruption of the site. However, since the project is still ongoing, perhaps the future may hold more archaeological surprises. The team has gained as much information as possible from the system used and the photomosaics produced, and even though the project has some drawbacks, in total, it was extremely successful in many ways.

\section{Results and Observations}

My research concluded that photogrammetry in underwater archaeology is an important method for the documentation and interpretation of an archaeological site. It was discovered that photogrammetric applications in underwater archaeology can be used for mapping a site, recording an area or artefacts, taking measurements, extracting site plans, photomosaics, or orthomosaics, illustrating the process of an excavation via 3D models, investigating the site's conditions or comparing new with old site data, and even for reconstruction purposes, dissemination, and education so as to raise public awareness. From all the articles examined, it has also been concluded that the majority of projects that use photogrammetry do not really share their work interactively and others do not share all the theoretical information needed for better interpretation of the models.

What is more, those who employ photogrammetry in archaeology are not only archaeologists; organisations, institutions, and companies are also involved. These results can be seen in Table 3. For instance, the Mars site 
was excavated in 2011 by experienced divers with mixed gases (Fig. 9) (Eriksson and Rönnby, 2017: 94), whereas volunteer workers were also involved in the James Matthews excavation (Fig. 10) (Baker and Henderson, 1979: 244). The Holland 5 submarine uploaded by the Nautical Archaeology Society (NAS) on Sketchfab in 2018 was used for educational purposes, as it uses links to the history of the site and annotations in order for users to be able to look at the model and gain information (Fig. 11). However, the small number of people who have seen it (87) creates additional concerns. It seems that models from the Maritime Archaeology Trust (MAT) appear to be more appealing, as these models have more than 500 views. This is probably because the NAS has only five uploaded models and eleven followers, whilst the MAT has uploaded 68 models and has 740 followers. Only this can show that the organisations are the ones tasked with attracting the public in order to set the ground for public engagement and cultural heritage awareness.

Another observation that was made was the fact that people do not react often on Sketchfab; comments are rare and the majority of likes recorded concerned MAT's model of the Gresham ship, and even so, did not exceed 62 (Fig. 12). The tags have to be precise and numerous. Furthermore, MAT's practice of including background information, external links, and annotations has been proved to be successful.

Having clarified the above, I can make more observations. Fewer articles have been published (13) than models uploaded on Sketchfab (57).Moreover, none of the 13 articles have uploaded any models on Sketchfab or other platforms, something that is my big concern.

Additionally, it is surprising that even though American publications were found, Americans have not used the Sketchfab platform as frequently as people from the UK. In particular, the majority of organisations that use 3D models to represent archaeology are from the UK: five UK archaeological organisations were present, compared with three from the USA, two from Malta, and one from Poland. Moreover, the UK organisations have an archaeological mission or are companies are cooperating with archaeologists, whereas the USA examples are more scientific and environmental organisations. Consequently, this difference in 3D model use is perhaps due to the organisations' different industry sector.

Another observation was the fact that the published articles about photogrammetry do not include any links or interactive PDFs within their publications in order to show to other researchers what they had actually produced. One could say that articles about iconography with no images to support the theory behind iconography are not valid. However, in photogrammetry experts are providing details about their research without showing their tangible results in the form of interactive material. It is quite disappointing to see these kinds of publications, which can only provide illustrations and no interactive material. Therefore, journals like the IJNA should have a system for including interactive material on their website, since each reader would have a better interpretation of a 3D model by looking at it on the screen.

The information gained from the articles is mostly archaeology-based, since they focus on the topography of the site (depth, date, nature of the site), whereas Sketchfab models are more focused on the technical form of 
the model uploaded, since they explain the vertices and the triangles4 of the model. If one looks at the Sketchfab data table, they can see that information such as characteristics of the site or visibility are not mentioned at all and some fields are completely empty. What is more, the purpose of the production of the models is not mentioned either. All these details can affect the way the public interprets the models and can prevent people from spending time viewing a model without the latter providing any background information at all.

Therefore, it has been demonstrated that when researchers write articles about an excavation, they focus either on the methodology of the excavation or on the methods of creating the model, and they sometimes publish different articles to emphasise different topics and address specific publics. However, by focusing only on one thing, either on the results of the project, the methodology, or the cargo, they could miss out on presenting with much detail another significant aspect of the project. This can create confusion in the public, whereas one evenly structured paper might be a better solution. A great example is the article of the Cape Stoba shipwreck (Kralj et al., 2016), which mainly examines its cargo and leaves a tiny section about the methodology the archaeologists followed underwater and the post-processing of the data obtained (Fig. 13).

Ten of the 13 projects found in IJNA (Table 1: https://1drv.ms/x/s!Av5VFeWTIJYWjDdLrbcdDVNNbspv) have used photogrammetry as their primary method, to investigate the wreck, examine its cargo and the circumstances of the wreck (Table 3). After the examination of all the uses of photogrammetry, the conclusion was made that it is considered an exceptional tool, especially when used in underwater archaeology where the visibility is low, due to the fact that it can facilitate projects through the provision of all the functions described above. The fact that archaeologists can illustrate the excavation process in order to have different representations of the trenches, as was done at the Mazotos wreck, gives them additional information and a different understanding of the site each time. Moreover, the advantage of using photogrammetry on very deep-water sites with ROVs or submarines makes the technique distinct from traditional techniques that can only be used in a certain depth for a certain time underwater. Digital photogrammetry was used in the Grand Ribaud F wreck in 2000 with the use of a submarine for the creation of a topographic map in order to display the bottom and locate the amphorae of the wreck (Drap and Long, 2001: 2-3). This led to a better interpretation of the site by archaeologists, since there was no pressure of time or limitation of underwater visibility.

Finally, the majority of the projects which have been published and used photogrammetry underwater seem to have been conducted by experts from the USA and Australia. The funding seems to have come from the same countries as well. More concretely, three projects were conducted by Australians with Australian financial aid and three projects were conducted by Americans with funding from the USA. A single exception is the Mars project, as it was conducted mostly by people from the USA, but with archaeologists from the UK and Sweden involved as well. Likewise, excavations in Turkey on both the Yassi Ada and Tektas Burnu sites were performed by American archaeologists and the funding was provided mostly from USA sources (Bass and Van Doorninck, 1969; Carlson, 2003). This is not considered to be a random process, though, since Americans might have more

$4 \mathrm{~A}$ triangle is the simplest polygon that is made up of three sides or edges connected by three vertices, making a three sided face. Triangles tend to pose a problem when subdividing geometry to increase resolution and when a mesh will be deformed or animated (D.T., n.d., 2018). 
funding, better experience, or they might be more concerned about the cultural heritage. Furthermore, the funding they obtained was diverse. As can be seen in Table 1 (https://1drv.ms/x/s!Av5VFeWTIJYWjDdLrbcdDVNNbspv), projects such as Yassi Ada had multiple sources in contrast with the James Matthews and Mazotos projects. The fact that those local to a wreck's location do not organise an excavation might mean that they do not have the necessary budget or that they are unable to get funding for political or governmental reasons. Therefore, other countries with more power can gain access and conduct the excavation for them. If the people who are in charge produce publications and 3D models of their research, the hidden archaeological areas will be widely known.

\section{Discussion}

As discussed above, it is not only archaeologists who conduct photogrammetry, but also organisations that are uploading models or creating virtual trails in order to share the knowledge with the world and engage the public with archaeology. This is another way to raise awareness about archaeology, something that can lead the public to respect and protect archaeology. Virtual trails for instance, such as the ones MAT and NAS uploaded on Sketchfab, or 3D model exhibitions of wrecks such as the Grand Ribaud F project could increase the public's interest and interpretation of a site. This is something archaeologists should work on in the future, as it seems that this minor change would create more publicity and funding accordingly, along with education. This argument is based on the many views that Sketchfab models have, compared to archaeological articles from the IJNA.

Now, after fifty years of experience and experimentation, archaeologists finally are able to take the photographs needed in only one day, as happened on the Mazotos wreck (Demesticha et al., 2014: 143-144). The fact that archaeologists are not publishing as much as they should is a limitation that depends on multiple things: little funding, small survey projects, limited excavations, or even the fear of artefact despoliation. This limitation though should be taken under serious consideration, since 'accessibility to archaeologists and the public' was the third most common aim of the case studies examined from journal articles (Table 3). Besides, if there are not many publications available, archaeologists will not be informed about new techniques, such as photogrammetry, or site discoveries. The most important obstacle observed was the fact that even when they publish, they do not add any interactive PDFs or links to the model they created, or when organisations publish a model, little information accompanies it. The way they use it, the fact they cannot combine these two together - publication with the 3D model or data - is therefore still problematic. One could think that these are two different things that are being used for different reasons: that publications are for academics and 3D models for the public. However, these two should always be combined together as an overall study, as the one complements the other. If the publications do not to include interactive data, the public will not be able to interpret archaeology from a site-plan alone, something that interferes with the raising of public awareness that archaeologists are trying to succeed.

The case study of the Mazotos shipwreck seems to have accomplished its aim with the use of photogrammetry. As explained previously, the project is considered an excellent example of using this method as it 'should' be 
used. This means that the team used all the functions photogrammetry offers, a feature no other case study in Table 1 has accomplished. However, the fact that they have not shared their data (photomosaic) in an interactive form is considered a limitation, as the public cannot extract as much information from a single photograph as it can from a 3D model.

On the other hand, the platform Sketchfab, which is based in USA and France, showed that the majority of shipwreck models have been uploaded by UK organisations (Fig. 14 and Fig. 15). Thus, the choice was truly scientific and not personal. The cases where people used photomosaics were included, since the technique is part of photogrammetry. Consequently, future work might be to conduct further research on photomosaics, in order to produce a more complete database of shipwreck sites that have used photogrammetry around the world.

\section{Conclusion}

Even though the aims of photogrammetry and tape measure trilateration are the same, it can definitely be said that photogrammetry changed the way archaeologists practice the discipline, along with the way they plan their projects. It has also changed the way people see and understand archaeology. Three-dimensional models can give people the understanding of the site itself, as well as the nature of the seabed, and the artefacts or the cargo. The results obtained from this study reflect the primary objectives that were set. The results add value to archaeological understanding about photogrammetry in underwater archaeology and can facilitate the field, if the considerations stated here are taken into account. Overall, photogrammetry can assist archaeologists to the fullest with all the functions it offers. In addition, the dissemination of archaeologists' work through publications will help promote archaeological research to a wider public. On one hand, it can encourage scientific discussions between experts and aid in the development of future scientific methods along with experimental archaeology, where experts can represent parts of a ship or a whole ship, either to gain a better understanding of its technology or to use it for a publication or a museum exhibition. On the other hand, it can contribute to public awareness through exhibitions or on the internet (Sketchfab), where it is accessible to all. The public is able to view a model and interpret a site, along with gaining an understanding about the way archaeologists work underwater. Furthermore, a photogrammetric model of a site can preserve its 'image', in case the site degrades in the future. In conclusion, photogrammetry has moved the discipline of archaeology forward. It is even allowing archaeologists to reach the deepest of sites, at $2000 \mathrm{~m}$ in the Black Sea (Pacheco-Ruiz et al., 2019). The minor problems affecting underwater photogrammetric surveys today, mostly equipment-related, should be solved in the near future, as technology is developing rapidly. As far as the people are concerned, they need to realise that archaeology is for all and needs to be shared in a way that everybody can interpret. Therefore, it should be tailored both to general audiences and experts. From this perspective, photogrammetry has revolutionised, and will continue to revolutionise, archaeological research and recording, especially underwater, since the models and the photomosaics can be used in so many ways to assist archaeological research and people's understanding.

\section{Acknowledgements}


I would like to thank the following for their various contributions to the production of this paper: Dr. Julian Whitewright, (Senior Teaching Fellow, University of Southampton, UK), Dr. Eleni Zimi, (Ass. Professor in Classical Archaeology, University of Peloponnese, Greece), Mark Beattie Edwards (CEO of the Nautical Archaeology Society), Alice de Vitry, Maria Michael, Miranda Richardson, and Bob Holtzman.

\section{Reference List}

Academia, 2019, What are AuthorRank and PaperRank? [Online] Available at: http://support.academia.edu/customer/en/portal/articles/2201342-what-are-authorrank-and-paperrank [Accessed 10.06.2019].

Adams, L. P. and Spirakis, A., 1997, Stereo photogrammetry, in J.F. Orr and J.C. Shelton (eds.), Optical measurement methods in biomechanics, 17-38. Boston: Springer.

Agisoft, LLC, 2018, Agisoft PhotoScan User Manual: Professional Edition, Version 1.4. [Online] Available at: http://www.agisoft.com/pdf/photoscan-pro_1_4_en.pdf

[Accessed 20.02.2018].

Albertz, J., 2001, Albrecht Meydenbauer-Pioneer of photogrammetric documentation of the cultural heritage. Berlin.

Al-Ruzouq, R., 2012, Photogrammetry for Archaeological Documentation and Cultural Heritage Conservation, in D. C. D. Silva (ed.), Special Applications of Photogrammetry, 136. Jordan.

Baker, P. E. and Green, J. N., 1976, Recording techniques used during the excavation of the Batavia. The International Journal of Nautical Archaeology and Underwater Exploration 5.2, 143-158.

Baker, P. and Henderson, G., 1979, James Matthews excavation. A second interim report. The International Journal of Nautical Archaeology and Underwater Exploration 8.3, 225-244.

Bass, G. F. and Van Doorninck, F. H. J., 1967, Cape Gelidonya: A Bronze Age Shipwreck. Transactions of the American Philosophical Society. American Philosophical Society, 1-177.

Bass, G. F. and Van Doorninck, F. H. J., 1969, Excavations of a Byzantine Shipwreck at Yassi Ada, Turkey, National Geographic Society Research Reports 1964, 9-20.

Bass, G. F. and Van Doorninck, F. H. J., 1971, A Fourth-Century Shipwreck at Yassi Ada. American Journal of Archaeology 75.1, 27-37.

Beltrame, C. et al. 2014, SVETI PAVAO Shipwreck: A 16th Century Venetian Merchantman from Mljet, Croatia. Oxford: Oxbow Books.

Beraldin J.A., G. Guidi, S. Ciofi, C. Atzeni, 2002, Improvement of metric accuracy of digital 3D models through digital photogrammetry. A case study: Donatello's Maddalena, In the First International Symposium on 3D Data Processing Visualization and Transmission, [Online], Italy, Institute of Electrical and Electronics Engineers Available: 10.1109/TDPVT.2002.1024155.

Bowens, A., 2009, Underwater Archaeology: The NAS Guide to Principles and Practice. Portsmouth: Nautical Archaeology Society, Blackwell Publishing. 
Carlson, D. N., 2003, The Classical Greek Shipwreck at Tektas Burnu, Turkey. American Journal of Archaeology 107.4, 581-600.

Cederlund, C. O. and Ingelman, C. S., 1973, The excavation of the Juthlomen wreck, 1970-71. The International Journal of Nautical Archaeology and Underwater Exploration 2.2, 301-327.

D.T., n.d. Modelling with Quads or Triangles - What Should I Use? [Online] Available at: https://www.vertheim.com/modeling-with-quads-or-triangles---what-should-i-use.html [Accessed 1008 2018]. Demesticha, S., 2009, Questions on Trade: The case of the Mazotos Shipwreck, in A. M. D. Guimier-Sorbet (ed.), Actes du Colloque Chypre à l'époque hellénistique et impériale Recherches récentes et nouvelles découvertes, 387-402. Nanterre-Paris: Cahier de Centre d'Études Chypriotes.

Demesticha, S., 2011, The 4th-Century-BC Mazotos Shipwreck, Cyprus: a preliminary report. The International Journal of Nautical Archaeology 40.1, 39-59.

Demesticha, S. et al., 2014, The 4th-century B.C. shipwreck at Mazotos, Cyprus: New techniques and methodologies in the 3D mapping of shipwreck excavations. Journal of Field Archaeology 39.2, 134-150.

Dostal, C., and Yamafune, K., 2018, Photogrammetric texture mapping: A method for increasing the Fidelity of 3D models of cultural heritage materials. Journal of Archaeological Science: Reports 20, 430-436.

Drap, P. and Long, L., 2001, Towards a digital excavation data management system: the "Grand Ribaud F" Estruscan deep-water wreck, in the Conference on Virtual Reality, Archaeology, and Cultural Heritage, 17-26, Glyfada, Greece, [Online] Available: 10.1145/584993.584997.

Eriksson, N. and Rönnby, J., 2017, Mars (1564): the initial archaeological investigations of a great 16th-century Swedish warship. The International of Nautical Archaeology, 46.1, 92-107.

Green, J. N., 1975, The VOC ship Batavia wrecked in 1629 on the Houtman Abrolhos, Western Australia. The International Journal of Nautical Archaeology and Underwater Exploration 4.1, 43-63.

Green, J. N. et al., 2002, Underwater archaeological surveying using PhotoModeler, VirtualMapper, different applications for different problems. The International Journal of Nautical Archaeology 31.2, 283-292.

Hunter III, E. J. W. and Jateff, E., 2016, From Battleship to Breakwater: post-military adaptive reuse of the Australian warship Protector. The International Journal of Nautical Archaeology 45.2, 423-440.

Ingelman-Sundberg, C., 1976, Preliminary report on finds from the Juthlomen wreck. The International Journal of Nautical Archaeology and Underwater Exploration 5.1, 57-71.

Kan, H. et al., 2018, Assessment and Significance of a World War II battle site: recording the USS Emmons using a High-Resolution DEM combining Multibeam Bathymetry and SfM Photogrammetry. The International Journal of Nautical Archaeology 47.2, 1-14.

Kralj, V. Z. et al. 2016, A Byzantine Shipwreck from Cape Stoba, Mlej, Croatia: an interim report. The International Journal of Nautical Archaeology 45.1, 42-58.

Moffitt, F. H., 1970, Photogrammetry (second edition). Seranton, Pennsylvania: International Textbook Company.

Muckelroy, K., 1978, New Studies in Archaeology: Maritime Archaeology. Cambridge: Cambridge University Press. 
Pacheco-Ruiz, R., Adams, J., Pedrotti, F., Grant, M., Holmlund, J., and Bailey, C., 2019, Deep sea archaeological survey in the Black Sea - Robotic documentation of 2,500 years of human seafaring. Deep Sea Research Part I: Oceanographic Research Papers 152. [Online] Available: 10.1016/j.dsr.2019.103087.

Skarlatos, D. et al., 2012, An 'Open' Method for 3D Modelling and Mapping in Underwater Archaeological Sites. International Journal of Heritage in the Digital Era, 1.1, 1-24.

Yamafune, K., Torres, R., and Castro, F., 2016, Multi-Image Photogrammetry to Record and Reconstruct Underwater Shipwreck Sites. Journal of Archaeological Method and Theory 23.4, 703-725.

Van Doorninck, F. H. J., 1976, The 4th-century wreck at Yassi Ada. An interim report on the hull. The International Journal of Nautical Archaeology and Underwater Exploration 5.2, 115-131

\section{Figures}

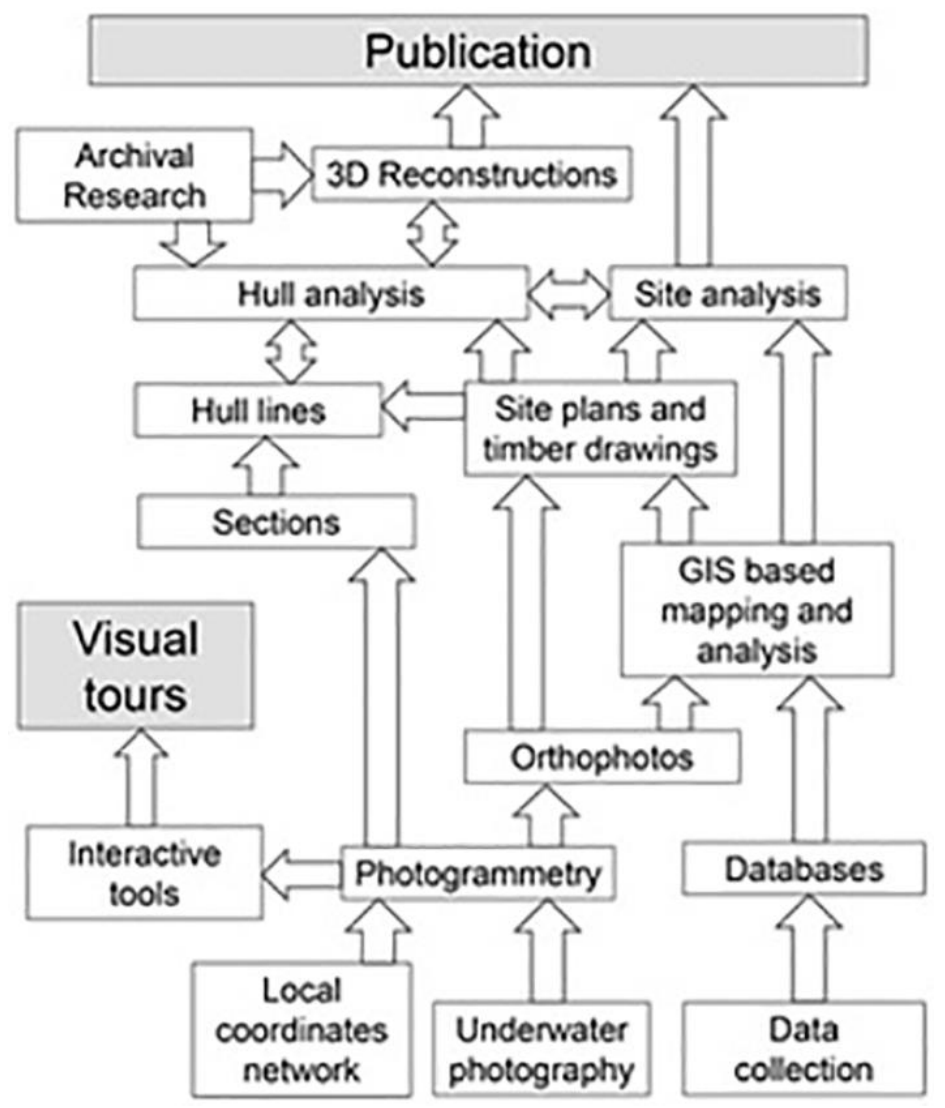

Figure 1. Suggested methodology. (Yamafune, et al., 2016) 


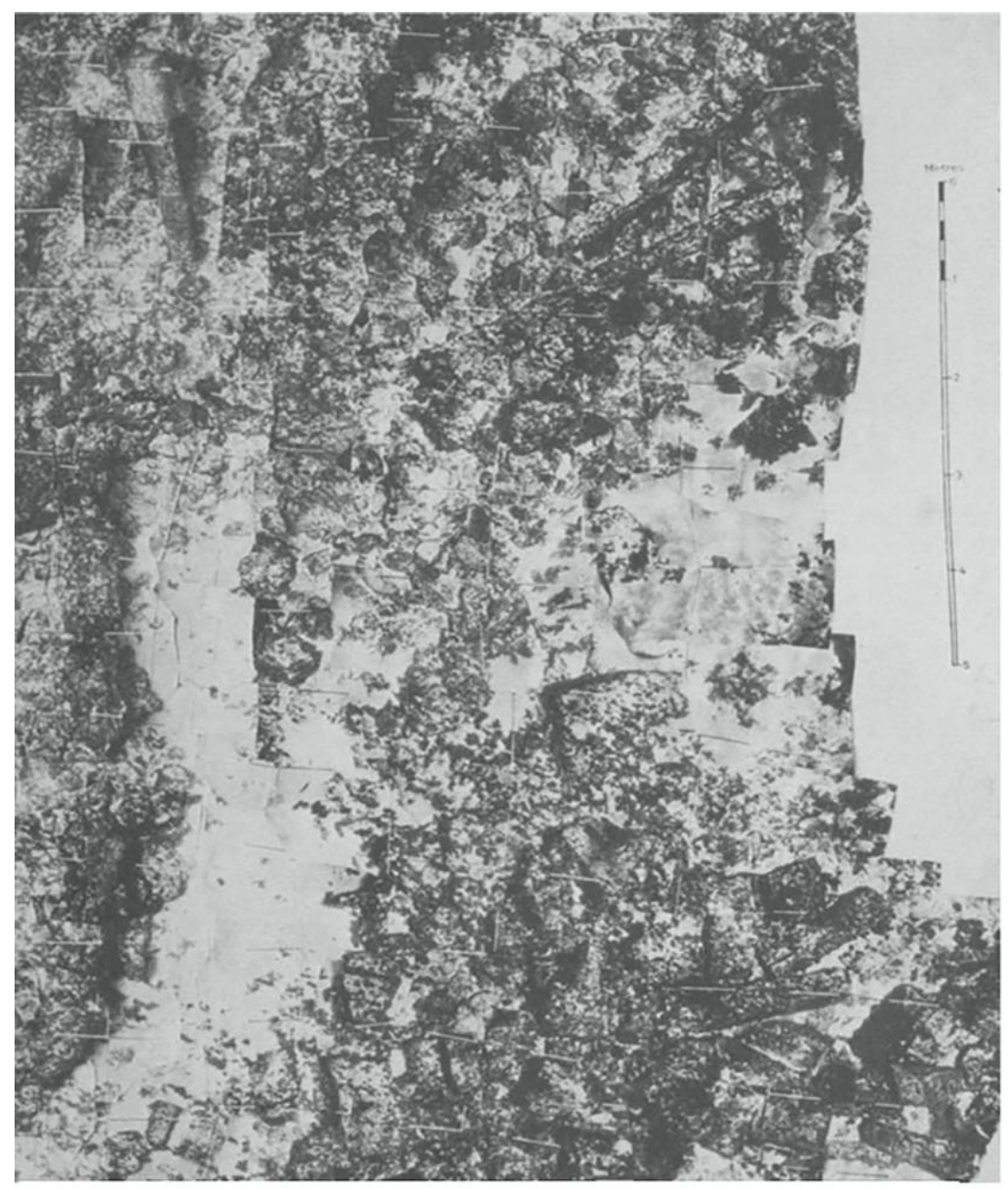

Figure 2. Photomosaic of southern half of Batavia wreck prior to excavation. (Baker and Green, 1976)

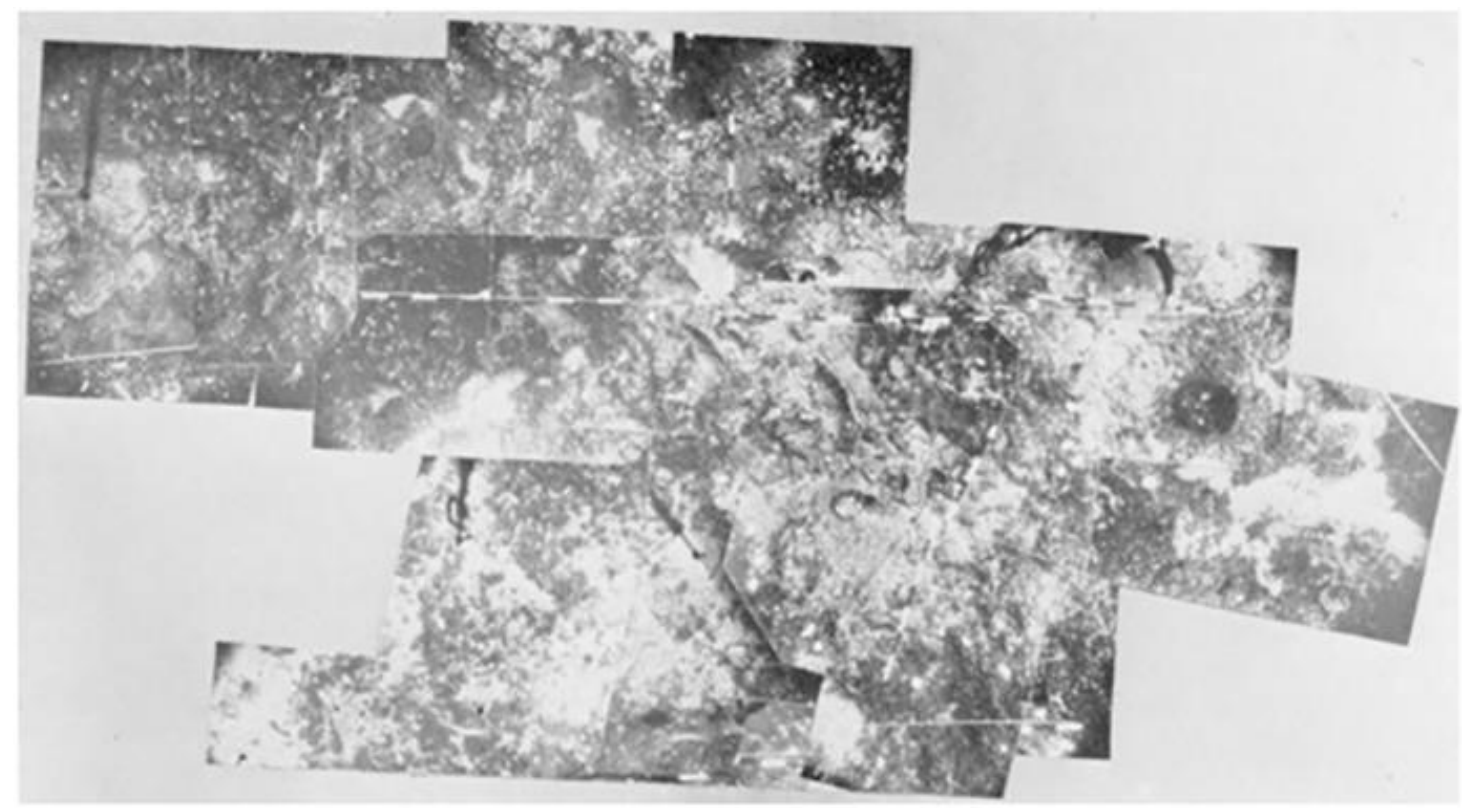

Figure 3. Photographic montage of the Cape Gelidonya wreck as when first seen; north at bottom. (Bass and van Doorninck, 1967) 


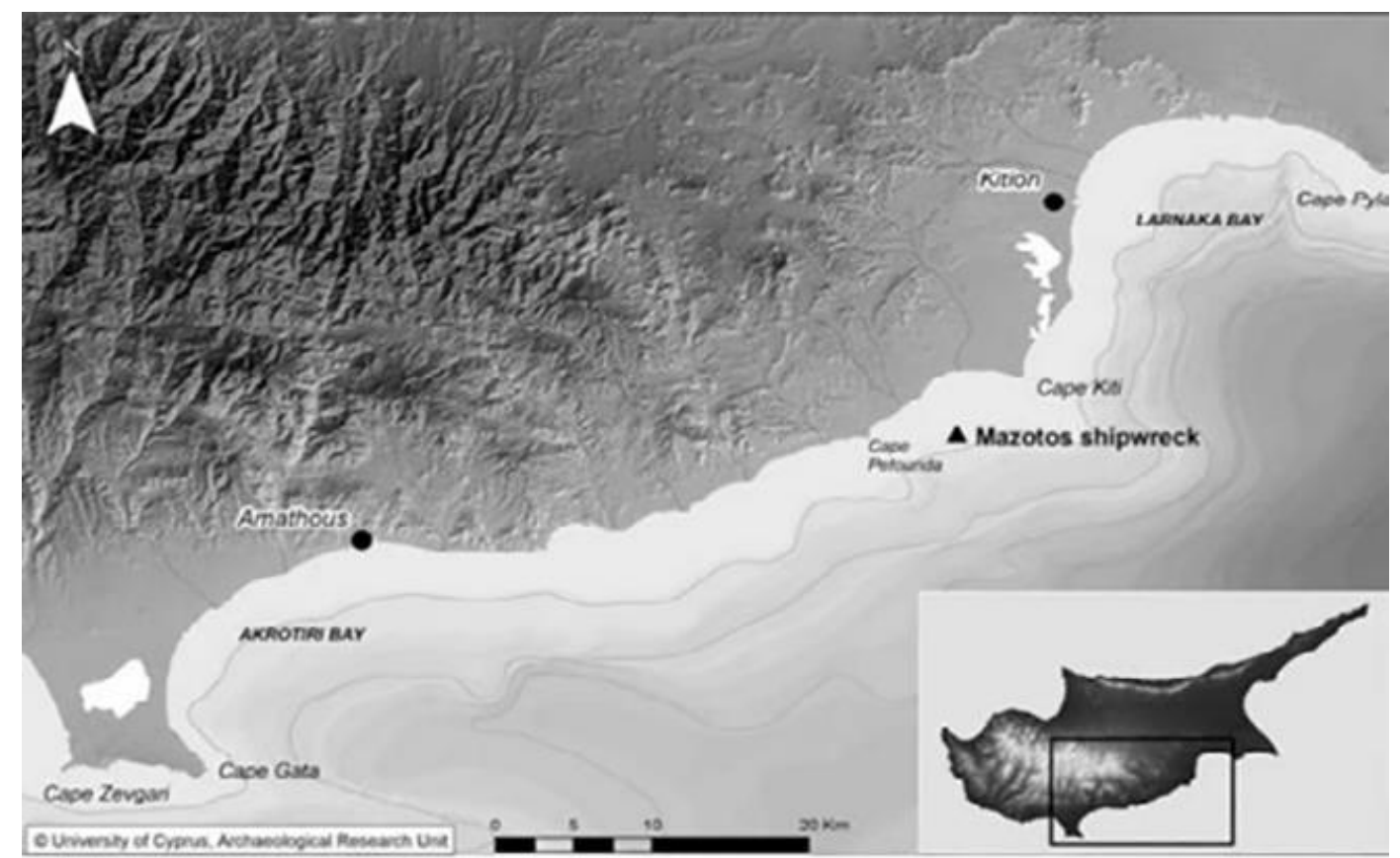

Figure 4. Map of the Mazotos site in Cyprus (Demesticha, 2010; ( A. Agapiou)

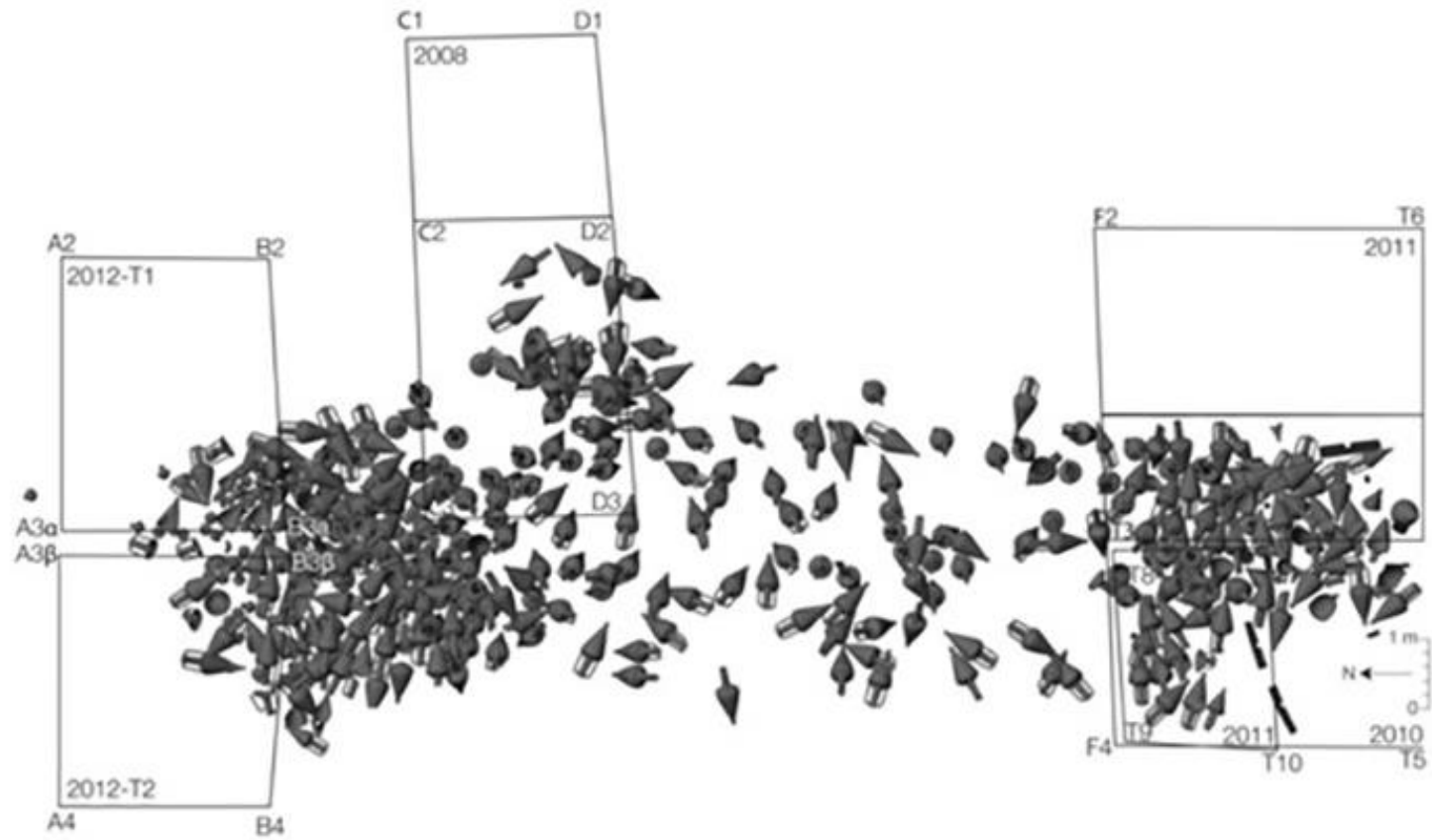

Figure 5. Site plan of the Mazotos shipwreck with the different excavation trenches marked. (Demesticha, et al., 2014) 


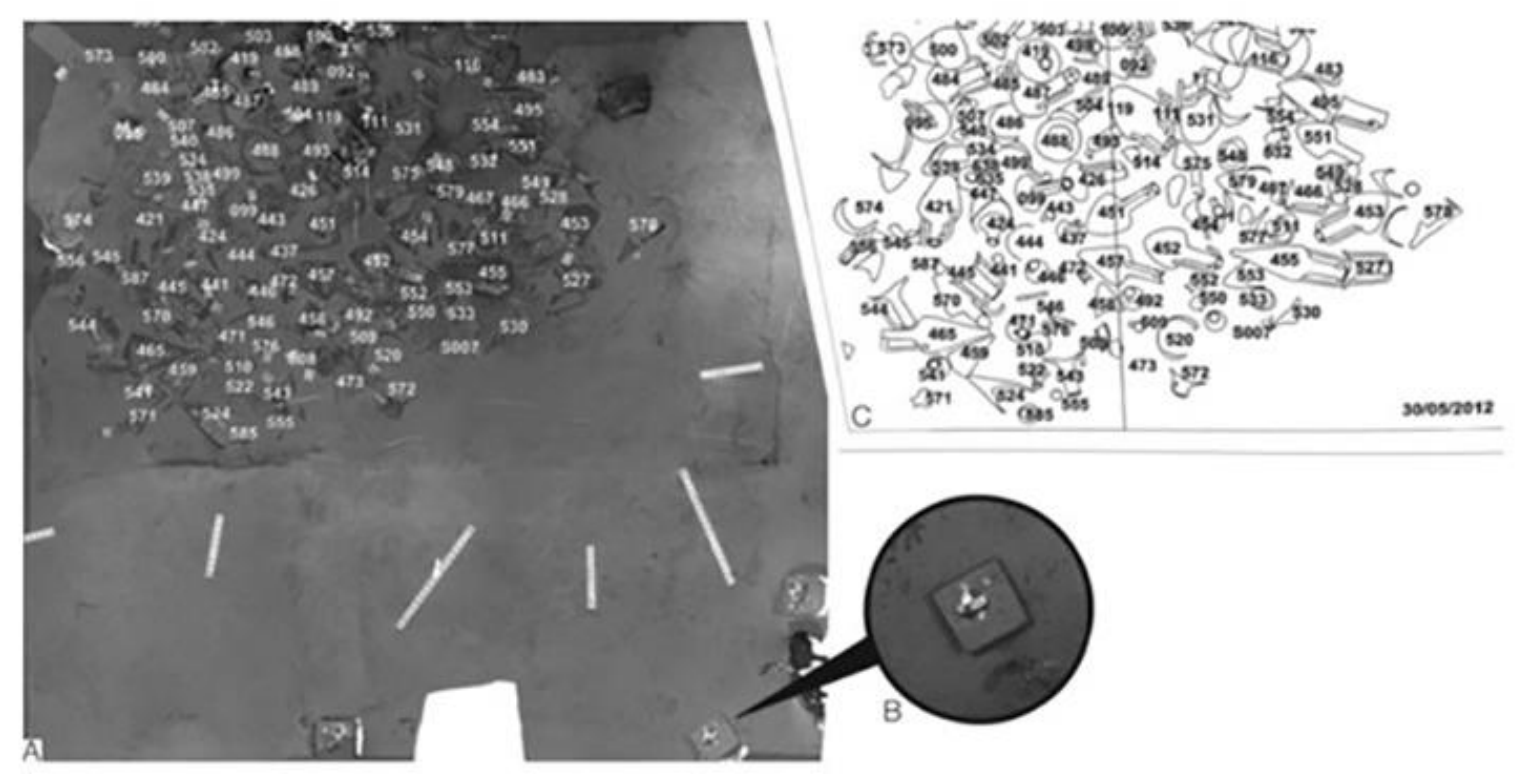

Figure 6. A) The orthophoto of the excavation trench of the Mazotos shipwreck, as it was documented at the end of one day during the 2012 excavation period. B) Image of six $25 \mathrm{~kg}$ cement blocks, produced from the orthophoto. (Demesticha, et al., 2014)
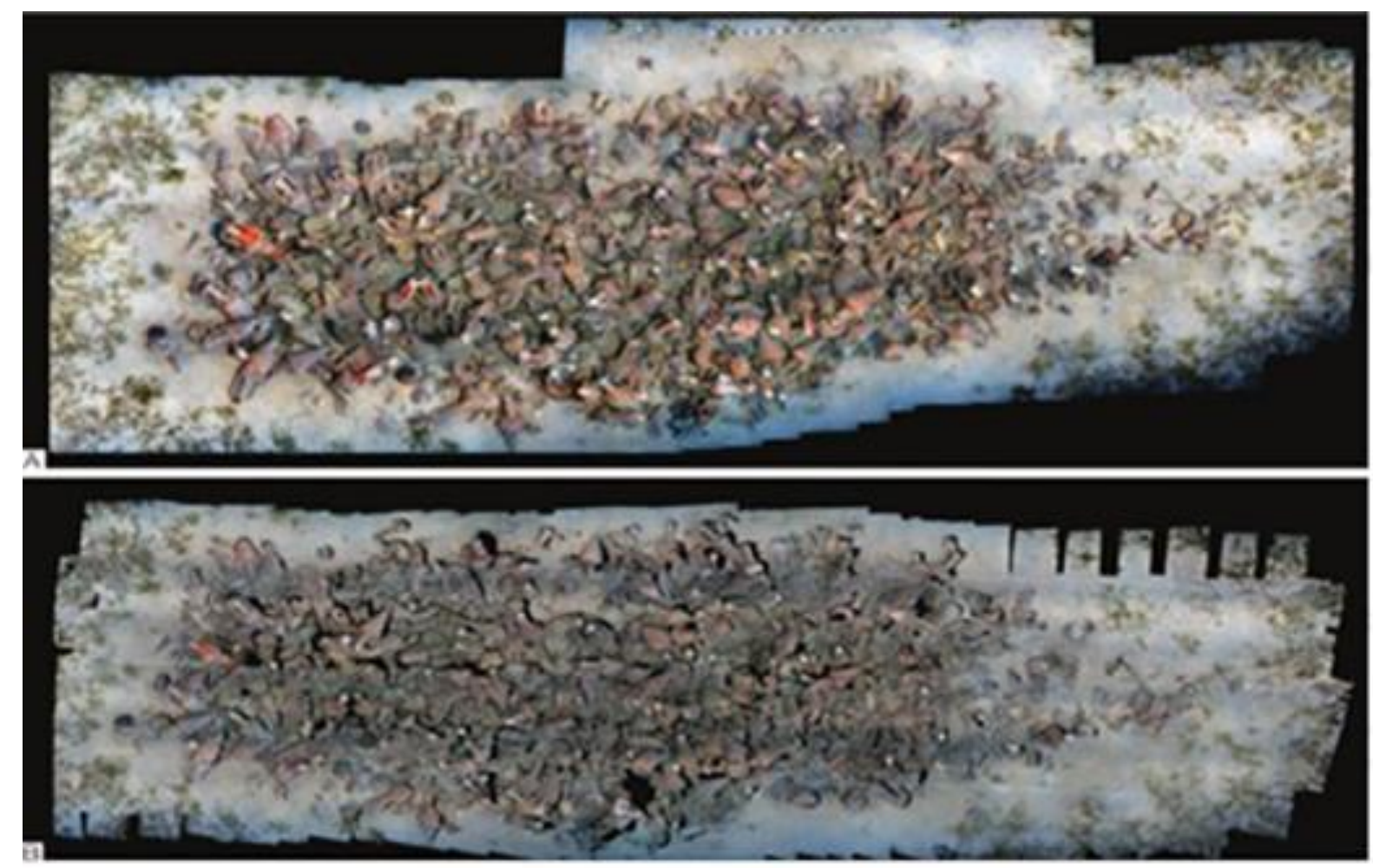

Figure 7. A photomosaic of the Mazotos wreck produced by photo stitching in 2007 and 2012. (Demesticha, et al., 2014) 


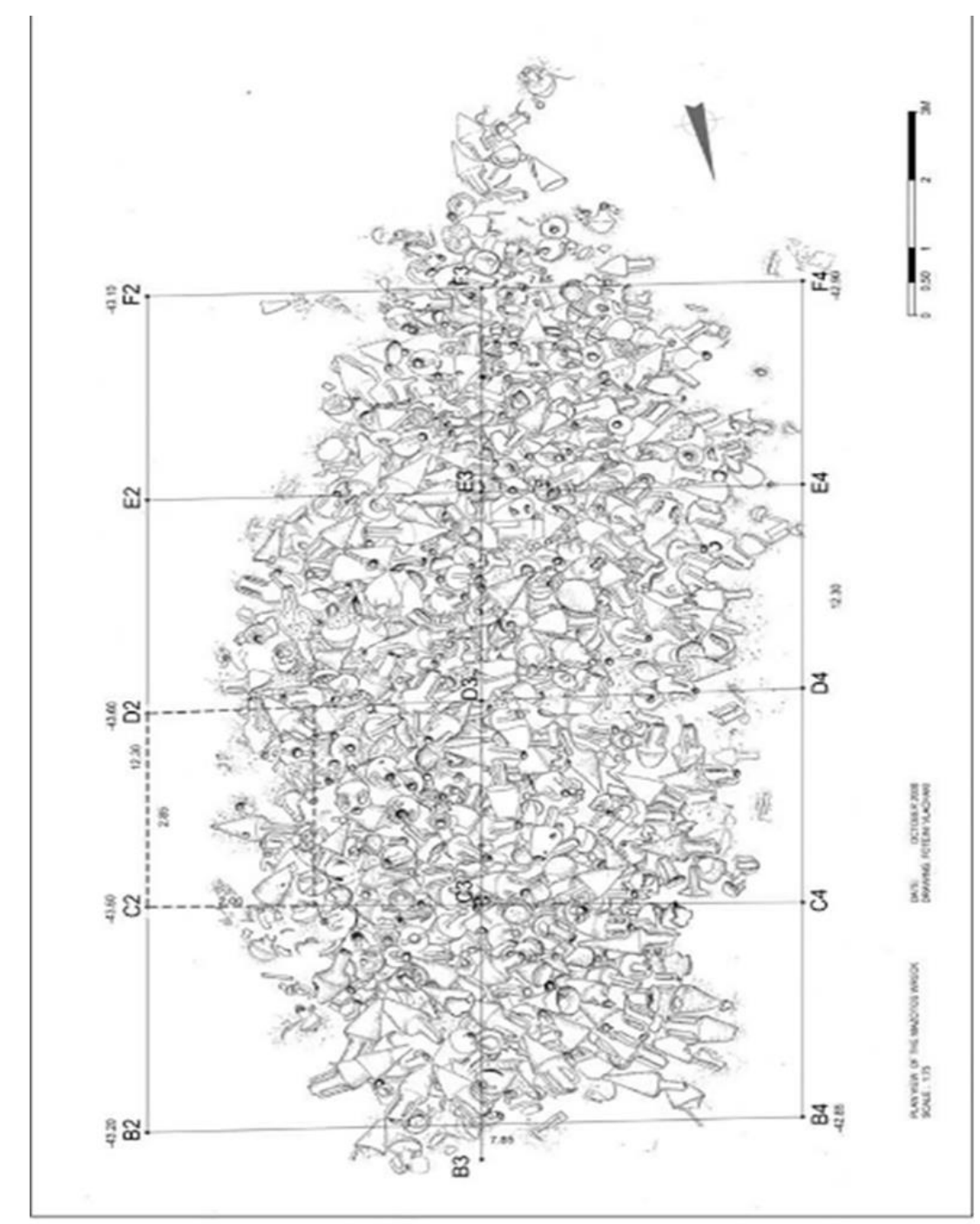

Figure 8. Two-dimensional site-plan of the Mazotos wreck, produced manually in 2010 from the photomosaic.

(Demesticha, 2010; ㅇ F. Vlachaki) 

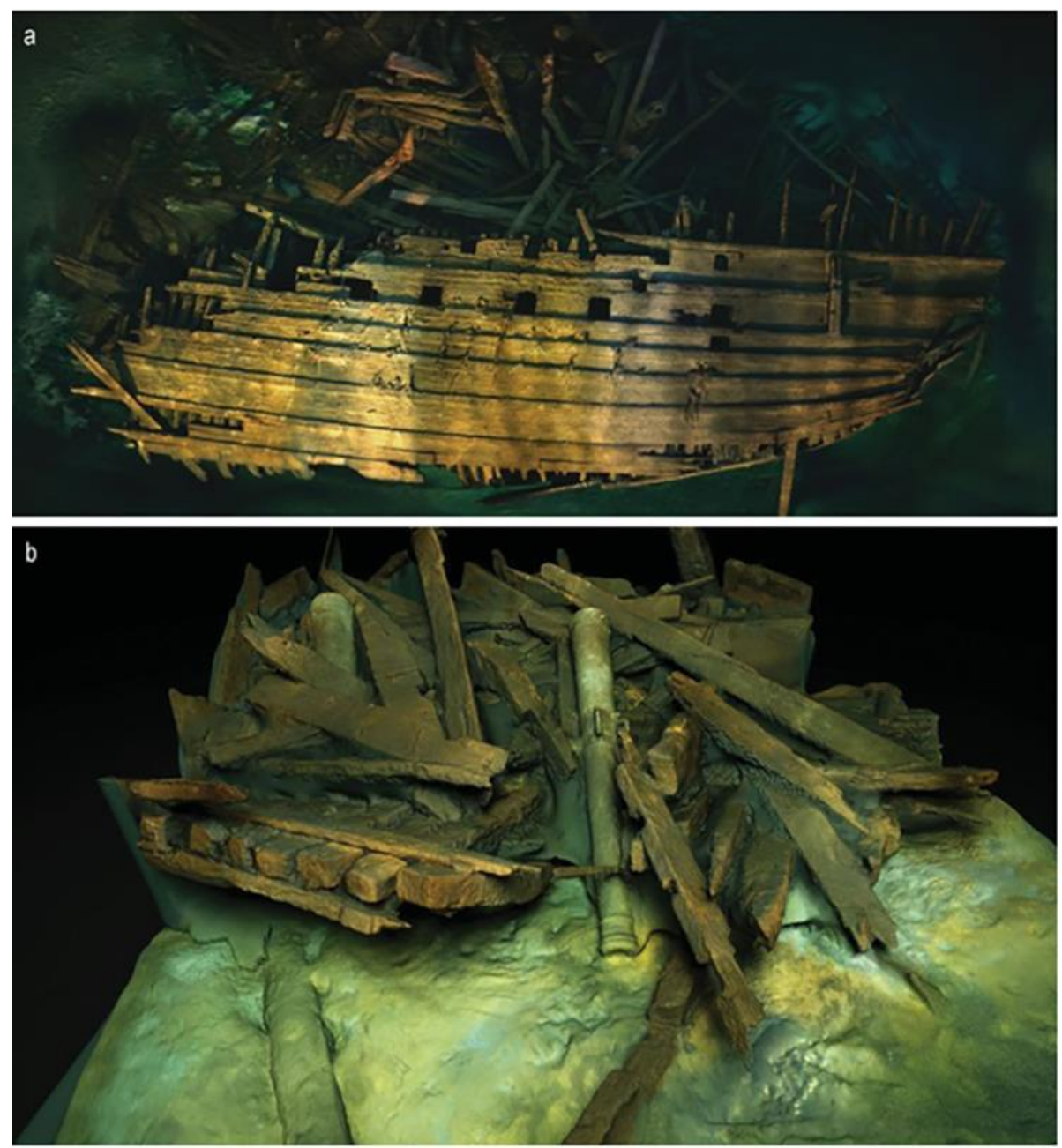

Figure 9. Photogrammetry of the port side and starboard site of the Mars wreck. (Eriksson and Ronnby, 2017; (C) Ingemar Lundgren) 


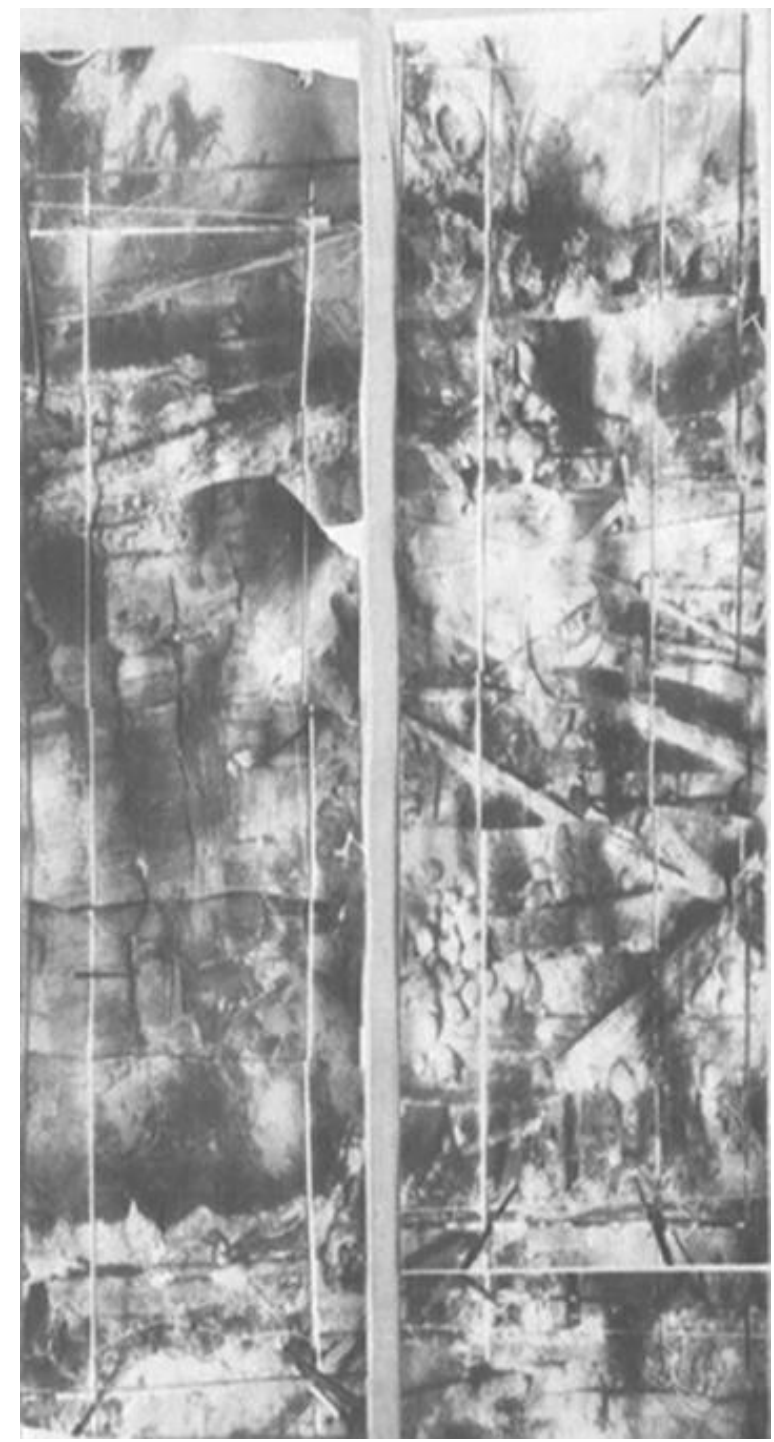

Figure 10. Photomosaic strips of two grids of the James Matthews wreck. (Baker and Henderson, 1979)

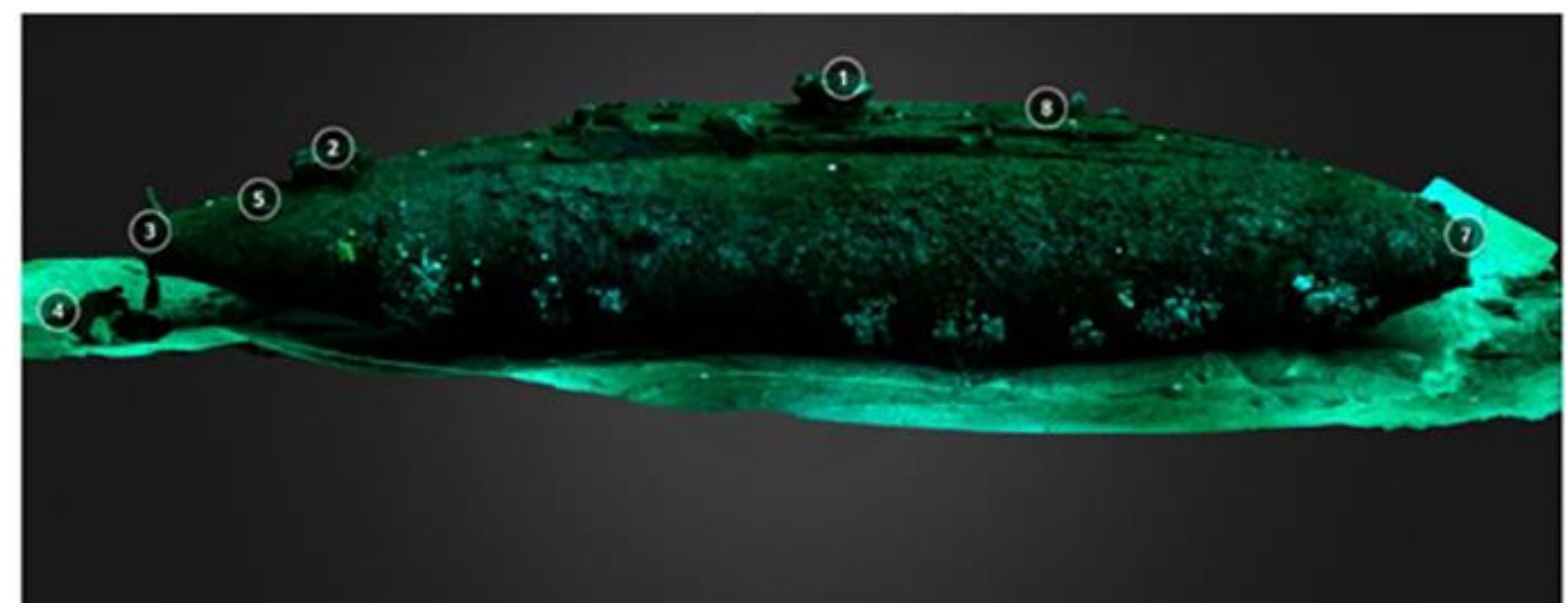

Figure 11. Holland No. 5 submarine. (C NAS, Sketchfab, 2018) 


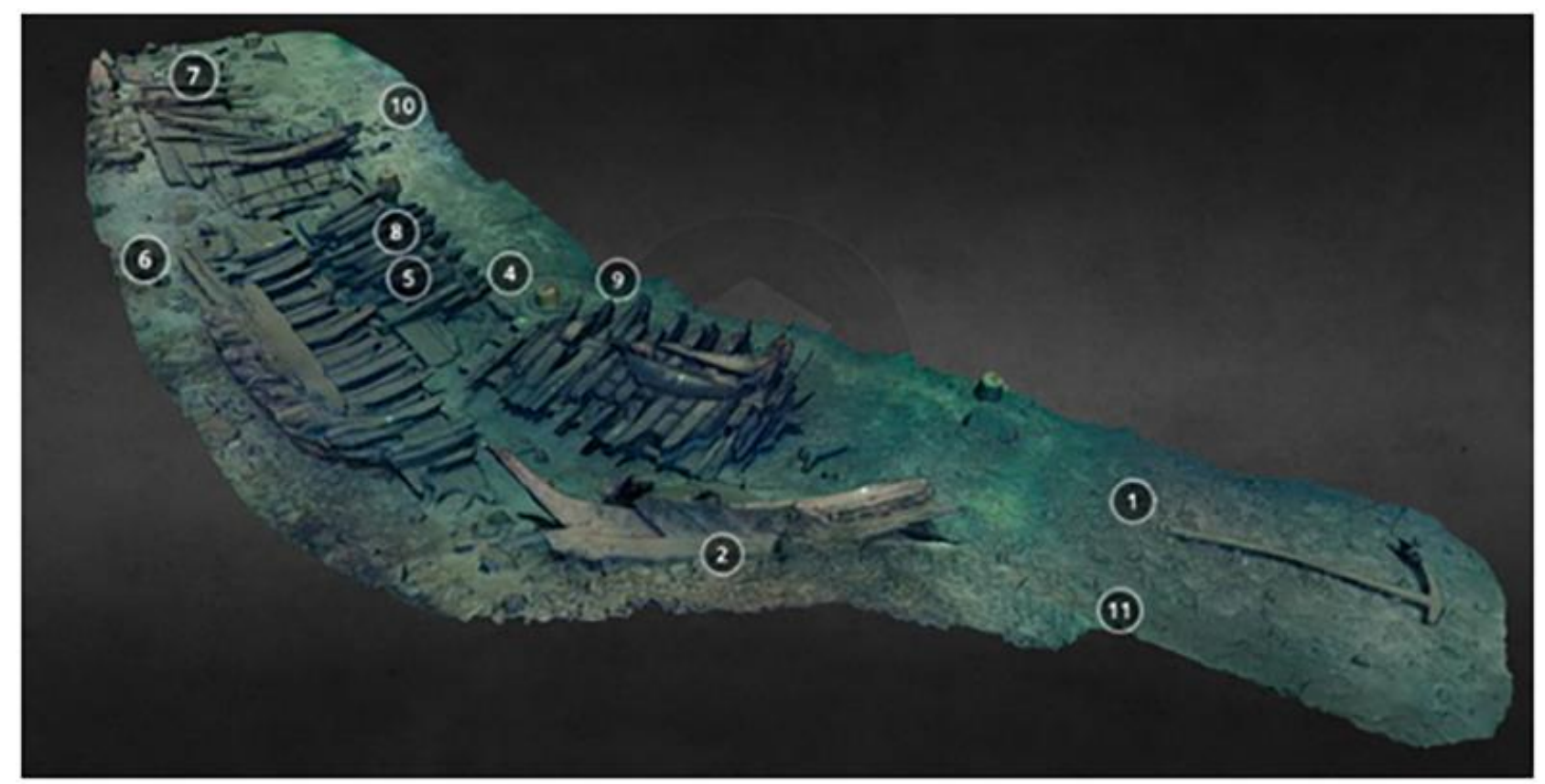

Figure 12. The Gresham ship. (C) MAT, Sketchfab, 2012)

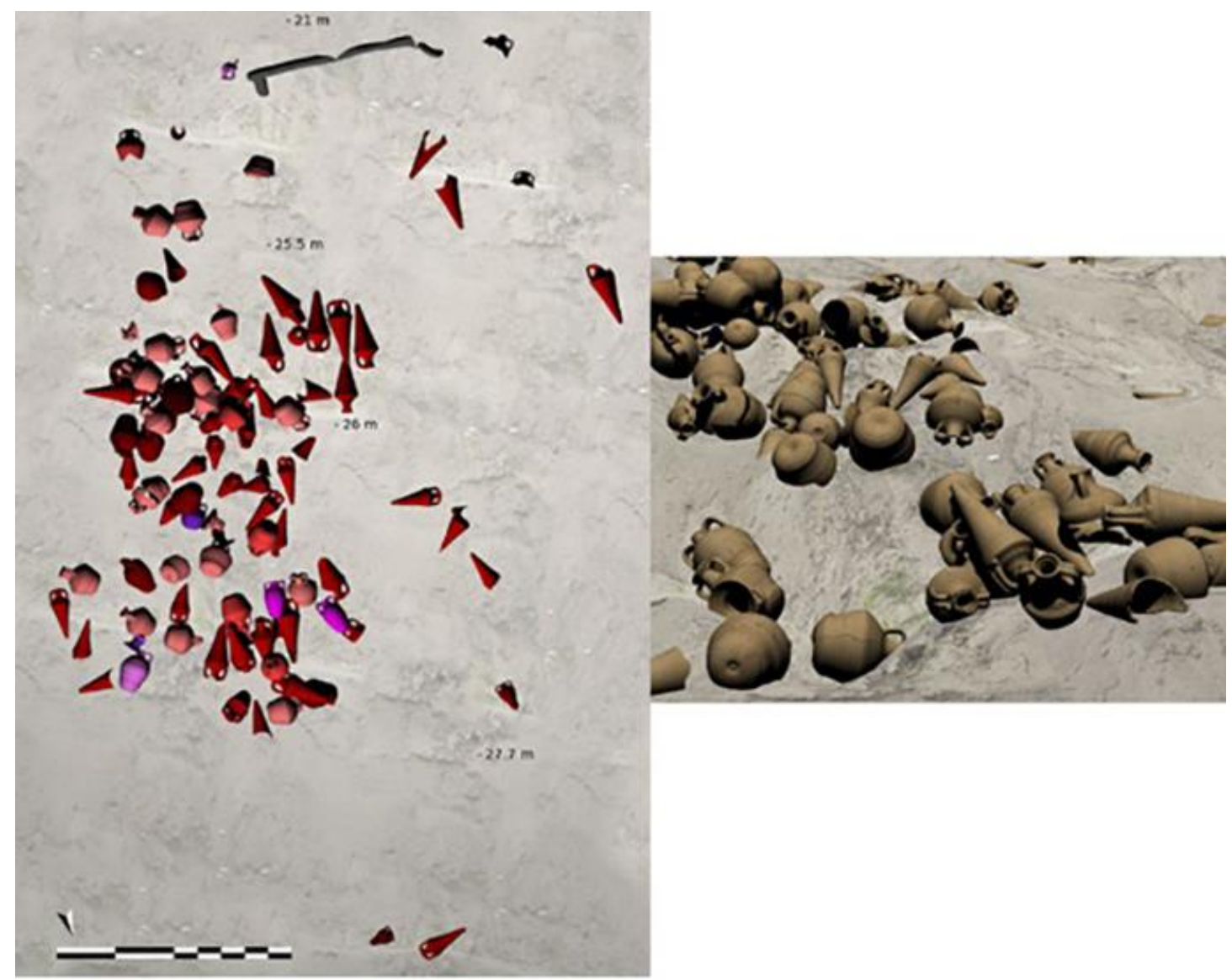

Figure 13. Plan of the Cape Stoba wreck-site, 2010-2014. Left: different amphora types are marked with different colours. Right: details of the 3D model of the shipwreck. (Kralj, et al., 2016; ( $)$ E. Costa) 


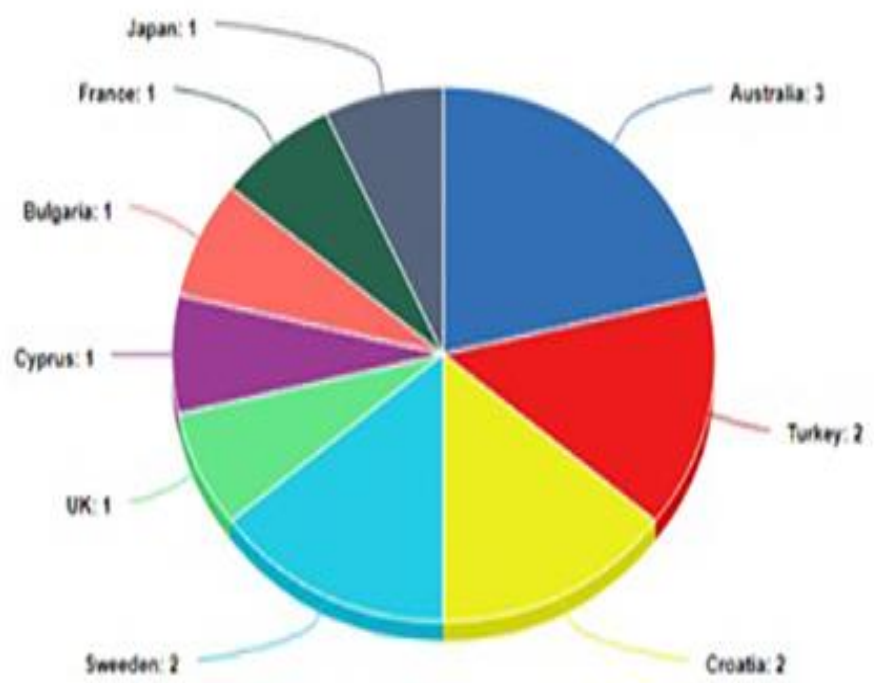

Figure 14. Distribution of sites that have used photogrammetry, based on data from Table 1 - Journal articles. (C) P. Lesgidi)

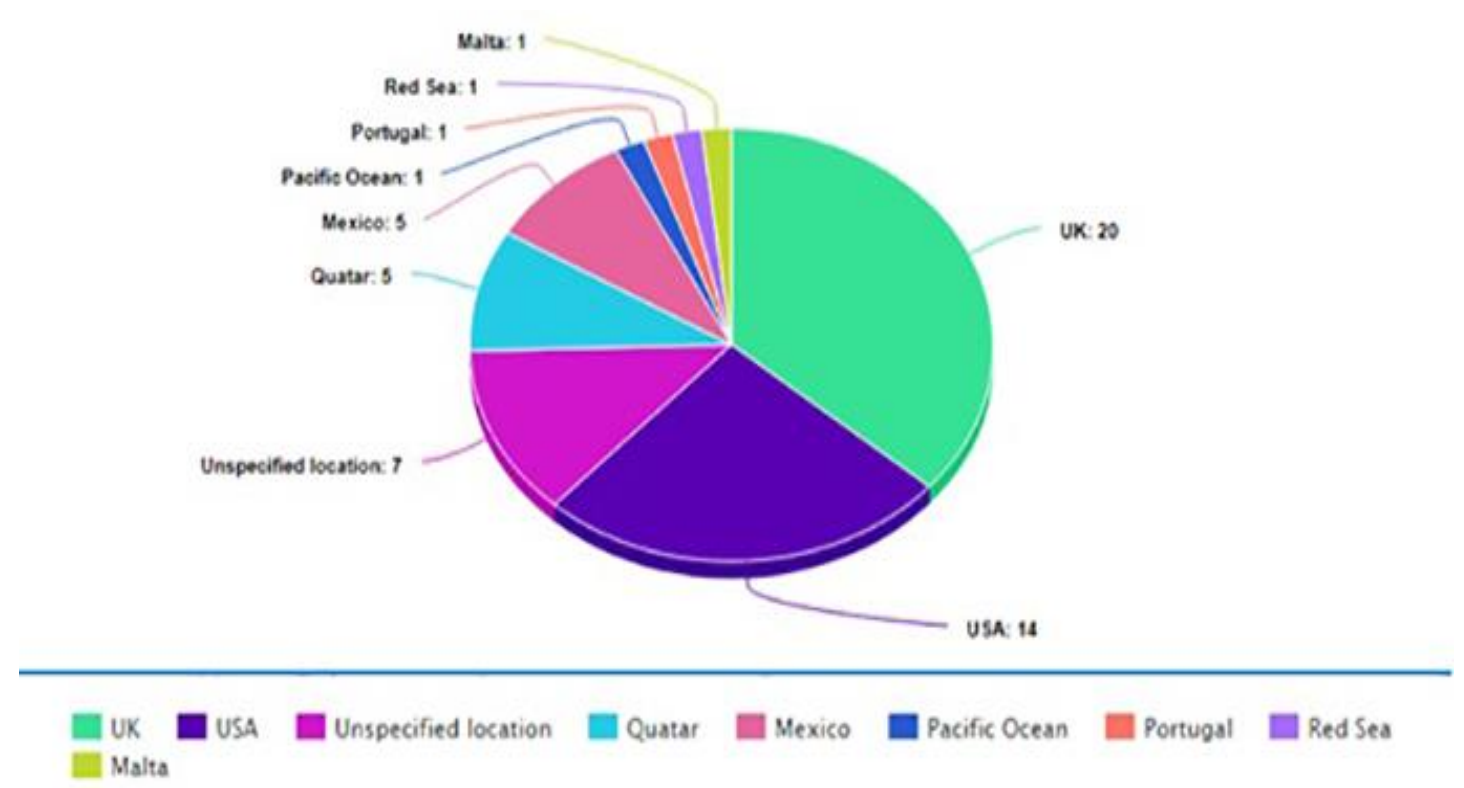

Figure 15. Distribution of sites that have used photogrammetry, based on data from Table 2 - Sketchfab. (C) P. Lesgidi) 
Table 3. Aims for practising photogrammetry

\begin{tabular}{|c|c|c|c|c|c|}
\hline $\begin{array}{l}\text { Investigation of } \\
\text { the wreck (history, } \\
\text { geomorphology, } \\
\text { position of the } \\
\text { wreck and cargo) }\end{array}$ & $\begin{array}{c}\text { Take } \\
\text { measurements \& } \\
\text { extract site plans }\end{array}$ & $\begin{array}{c}\text { Make it accessible } \\
\text { to archaeologists } \\
\& \text { public }\end{array}$ & $\begin{array}{c}\text { Documentation of } \\
\text { the hull }\end{array}$ & Excavate & $\begin{array}{c}\text { Record \& } \\
\text { reconstruct } \\
\text { fragments }\end{array}$ \\
\hline Juthlomen & Mazotos & Mars & James Matthews & 7th C. Yassi Ada & Batavia \\
\hline Mazotos & Mars & Grand Ribaud F & Cape Stoba & & \\
\hline Tektas Burnu & 4th C. Yassi Ada & Protector & & & \\
\hline Sveti Pavao & Juthlomen & & & & \\
\hline Emmons & $7_{\text {th C. Y }}$ & assi Ada & & & \\
\hline
\end{tabular}

